\title{
Effect of Deposition Voltage on Layer Thickness, Microstructure, Cu/Ni Sheet Resistivity of Deposition Results by Magnetic Field Electroplating Assisted Technique
}

\author{
Willi Anindita Wijanarka ${ }^{1 *}$ and Moh Toifur \\ ${ }^{1}$ SMP Muhammadiyah 1 Mlati \\ Jl. Magelang Km. 7.5, Sleman, Yogyakarta, Indonesia \\ ${ }^{2}$ Master Program of Physics Education, Universitas Ahmad Dahlan \\ Jl. Pramuka No. 42, Yogyakarta, Daerah Istimewa Yogyakarta, Indonesia \\ *Email: willy.anindito@yahoo.com
}

\begin{tabular}{ll}
\hline \hline \multicolumn{1}{c}{ Article Info } & \multicolumn{1}{c}{ ABSTRACT } \\
\hline Article History & The purpose of this research is to make the Cu/Ni thin layer as an alternative to basic \\
Received Jan 12, 2020 & RTD materials through electroplating methods assisted by magnetic fields. \\
Revised Jun 6, 2020 & Electroplating was carried out with variation in deposition voltage ranging from 1 to 5 \\
Accepted Jun 6, 2020 & V. The results of this study indicate that the deposition voltage applied to the coating \\
\hline & affects the thickness, sheet resistivity, and microstructure of the coating. Thickness \\
Keywords: & increases with increasing deposition voltage. The diffraction intensity and crystal size \\
Electroplating & tend to increase with increasing deposition voltage. The distance between Bragg \\
Magnetic field & planes after the coating is almost equal for all samples. The highest sheet resistivity \\
Sheet resistivity & was obtained in the coating sample with a 4-volt deposition voltage. \\
\hline \hline
\end{tabular}

To cite this article:

W. A. Wijanarka and Moh Toifur, "Effect of Deposition Voltage on Layer Thickness, Microstructure, Cu/Ni Sheet Resistivity of Deposition Results by Magnetic Field Electroplating Assisted Technique," Indones. Rev. Phys., vol. 3, no. 1 , pp. 23-29, 2020.

\section{Introduction}

Sensor are an important product of environmental monitoring. Copper $(\mathrm{Cu})$ and Nickel (Ni) can be alternative materials in making low-temperature sensors instead of expensive platinum. This is because copper can be used to measure temperatures as low as $-234.5{ }^{\circ} \mathrm{C}[1]$ with a linear response. Nickel can also be used as a temperature sensor in the range of $-200{ }^{\circ} \mathrm{C}$ to $320{ }^{\circ} \mathrm{C}$ [2].

Nickel can be superimposed on copper by electroplating method to form a thin layer of $\mathrm{Cu} / \mathrm{Ni}$. Copper and nickel have almost the same atomic size (0.1278 $\AA$ for copper and $0.1246 \AA$ for a nickel) and both have Face Centered Cubic (FCC) lattice shapes [3]. The $\mathrm{Cu} / \mathrm{Ni}$ film formed from the combination of the two materials will have a very strong inter-surface adhesion force [3].

The study that examines the effect of deposition voltage on the resistivity and thickness of the layers formed in the manufacture of $\mathrm{Cu} / \mathrm{Cu} / \mathrm{Ni} / \mathrm{Ni}$ thin films with a voltage variation of 1.5 to $5.5 \mathrm{~V}$ was done [4]. Through this research it is known that the greater the deposition voltage the layer thickness and resistivity increase. The effect of voltage on the thickness of the chrome coating on the steel plate with a variety of the voltage of 1.5 to $3.5 \mathrm{~V}$ shown that the thickness of the layer is directly proportional to the deposition voltage [5]. However, the data in the study [5] show that in a certain voltage range for deposition times 5,10 , and 15 minutes no increase in layer thickness results even though the voltage is increased. The studies mentioned above have not included the influence of external magnetic fields.

Electroplating research that includes the influence of external magnetic fields in the manufacture of $\mathrm{Ni}-\mathrm{Co}$ thin films proven that the application of an external magnetic field caused an increase in mass transport and the rate of electro deposition of metals [6]. This study also examined the effect of the magnetic field on the regularity of the crystal structure on nickel electro deposition. Through this research, it is known that by applying a magnetic field will prevent holes in the layer caused by the reaction of hydrogen evolution so that the layers formed are denser. However, the effect of coating resistivity has not been studied. Electroplating research on coating copper plates with nickel which includes the influence of external magnetic fields with variations in deposition current density proved that the application of an external magnetic field makes the nickel layer formed thicker and the sheet resistivity to be higher when compared without the application of an external magnetic field [7]. However, this research has not yet examined the effect on the regularity of crystal structures.

This research is expected to study thickness, microstructure, and sheet resistivity of the $\mathrm{Cu} / \mathrm{Ni}$ layer produced from electrodeposition prosses with a variation of deposition voltage and 200 gauss magnetic fieldassisted. 


\section{Theory}

\section{The Effect of Deposition Voltage on the Electroplating Process}

The relation between current density $(J)$ and deposition voltage $(V)$ is illustrated by the graph in Figure $1[8]$.

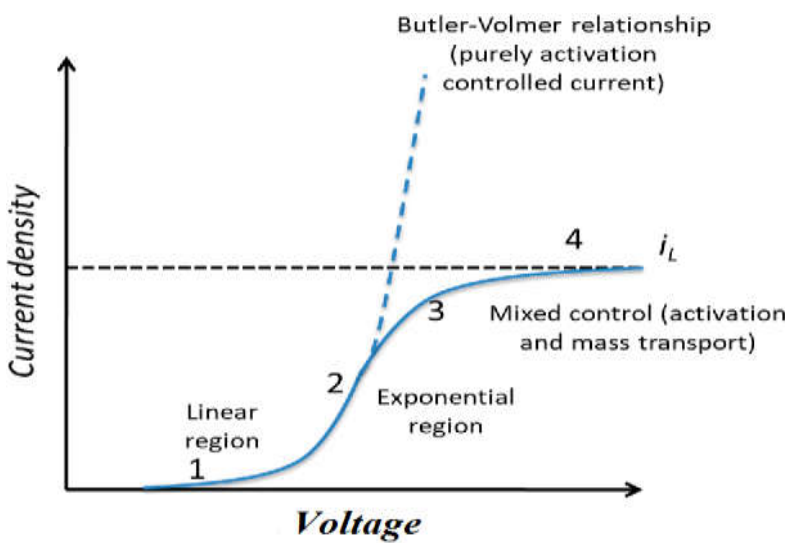

Figure 1. Graph of the relationship of current density to deposition voltage

There is a range of curves in which the current density is linearly related to deposition voltage called the linear region. There is also a range of curves where the current density is exponentially related to deposition voltage called the exponential region. The relationship between the thickness of the formed layer $(\delta)$ to the current density $(J)$ satisfies the equation (1).

$\delta=\frac{J t M}{N F \rho}$

where:

$t=$ coating time

$M=$ molar mass of the deposited element or metal

$N=$ quantity of electrons transferred

$\rho=$ layer mass density

$F=$ Faraday constant $(96485.33212 \mathrm{C} / \mathrm{mol})$

At the low deposition voltage range, the thickness of the formed layer increases linearly with increasing voltage, then when the voltage is increased the layer thickness increases exponentially.

Ideally, the growth rate of the initial deposit is faster than the rate of deposit formation afterward. In conditions of too low a voltage, the initial deposit formation takes place too slowly, so that the subsequent deposit begins to form before the initial deposit is formed perfectly [9]. This can result in the formation of deposits in the form of rough crystals. Meanwhile, when the voltage begins to increase, the rate of initial deposit crystal formation begins to increase so that the possibility of deposits becoming more fine-grained [9].

Too high voltage results in concentration polarization, which is the emptying of the solution zone around the cathode of ions, so that growth tends to occur at a higher zone of concentration which results in deposit growth in the form of small groups of crystals, resembling trees [9]. Too high a voltage can also result in overheating resulting in a burning deposit with a marked black color.

The Effect of Application of the External Magnetic Field on the Electroplating Method. By applying an external magnetic field to the electroplating process, three forces arise in the system that depends on the interaction between the moving ions and the magnetic field, namely the electrokinetic force $\left(\bar{F}_{E}\right)$, magnetic damping force $\left(\bar{F}_{D}\right)$, and the Lorentz force $\left(\bar{F}_{L}\right)$ that acting on each ion.

Electrokinetic force satisfies the equation (2).

$F_{E}=\frac{\sigma_{d} E_{\Pi}}{\delta_{0}}$

where $\sigma_{d}$ is the charge density of the diffusion layer, $E_{\Pi}$ is a non-electrostatic induction field, and $\delta_{0}$ represents the thickness of the diffusion layer. As for the magnetic damping force, it is defined as equation (3).

$\overline{F_{D}}=\sigma \bar{v} \times \bar{B} \times \bar{B}$

where $\sigma$ a solution conductivity, $\bar{v}$ as a velocity of ion, and $\bar{B}$ as magnetic field. The Lorentz force acting on each ion satisfies equation (4).

$\bar{F}_{L}=q \bar{v} \times \bar{B}$

with $q$ an ionic charge.

If the direction of the magnetic field vector is parallel with the ion velocity vector then the Lorentz force is zero, whereas for the direction of the magnetic field vector perpendicular to the ion velocity vector the direction of the Lorentz force is shown in Figure 2.

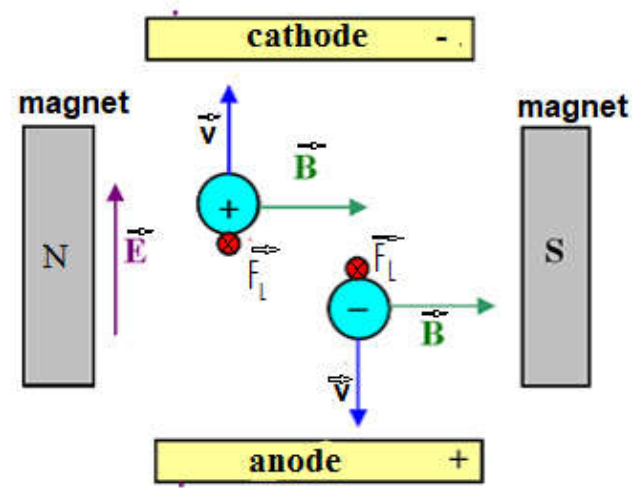

Figure 2. Diagram showing the direction of the Lorentz force (direction away from the reader) due to the influence of the magnetic field on ions moving perpendicular to the magnetic field vector.

Particles that move under the influence of a constant magnetic field in the direction of the velocity vector that 
forms a certain angle to the magnetic field vector have a velocity vector component whose direction is perpendicular to the magnetic field and velocity vector components whose direction is parallel to the direction of the magnetic field. With the Lorentz force, the particle velocity component whose direction is perpendicular to the direction of the magnetic field vector makes the particles move in a uniform circular motion. While the particle velocity component whose direction is parallel to the direction of the magnetic field vector is not affected by Lorentz's force so it keeps moving straight. The combination of these two kinds of motion causes a helical-shaped particle trajectory with an axis parallel to the magnetic induction vector or magnetic field strength vector $(\bar{H})$.

When an external magnetic field is applied, the magnetohydrodynamics effect occurs which results in the evolution of hydrogen gas. This evolution led to the depletion of the Nernst diffusion layer which satisfies equation (5).

$\delta_{D} \approx 1.59\left(\rho R v^{2 / 3} D^{1 / 3}\right)^{1 / 3}(n F C B)^{-1 / 3}$

where $\delta_{D}$ a nernst diffusion layer, $\rho$ electrolyte density, $R$ the working radius of the electrolyte, $D$ the electrolyte diffusivity, $n$ as a number of electrons are transported during the process, and $C$ the concentration of electroactive ions in solution.

This depletion causes a reduced screening effect that increasing in diffusion mass transport $\left(J_{\text {diff }}\right)$ that satisfies equation (6).

$$
J_{\text {diff }}=D\left(C-C_{e l}\right) / \delta_{0}
$$

where $D$ electrolyte diffusivity and $C_{e l}$ electroactive ion concentration near the working surface of the electrode (in this case the cathode).

Application of Permanent Perpendicular Magnetic Field (PPMF) in the electroplating process in a solution medium whose concentration is not uniform gives rise to paramagnetic forces $\left(\bar{F}_{p}\right)$. While the non-uniform magnetic field in the process creates a field gradient force $\left(\bar{F}_{B}\right)$. The paramagnetic force satisfies equation (7).

$$
\bar{F}_{p}=\frac{\chi_{m} c B^{2} \bar{\nabla} c}{2 \mu_{0}}
$$

The field gradient force satisfies equation (8).

$$
\bar{F}_{B}=\frac{\chi_{m} c B \bar{\nabla} B}{\mu_{0}}
$$

where $\chi_{m}$ molar susceptibility, $B$ magnetic field strength, $c$ concentration, $\bar{\nabla} B$ magnetic field gradient, $\bar{\nabla} c$ concentration gradient arising due to changes in solution concentration with respect to distance, and $\mu_{0}$ as vacuum permeability.

\section{Method}

This research was carried out from January to November 2019. Making $\mathrm{Cu} / \mathrm{Ni}$ samples by electroplating method assisted by external magnetic fields, thickness measurement, and characterization of sheet resistivity for $\mathrm{Cu}$ and $\mathrm{Cu} / \mathrm{Ni}$ produced was carried out at the Sentral Laboratory of Physics Education at Ahmad Dahlan University. The microstructure characterization of $\mathrm{XRD}$ from the $\mathrm{Cu} / \mathrm{Ni}$ thin layer produced was carried out in the PSTBM Batan Serpong. The object of this study was to observe the effect of deposition voltage on the thickness, sheet resistivity, and microstructure of $\mathrm{Cu} / \mathrm{Ni}$ thin films generated by electroplating methods assisted by external magnetic fields.

The first step in sample preparation is to create a $(10$ $\mathrm{x} 1.3$ ) $\mathrm{cm}$ cutting sticker design on the $\mathrm{Cu}$ plate. Parts of the plate that are not attached to the sticker are dissolved using $\mathrm{FeCl} 3$ solution, then cleaned with aquades. The electroplating process is carried out with variations in Voltage (V), the Voltage used is 1, 2, 3, 4, and $5 \mathrm{~V}$ in the electroplating process with 200 gauss magnetic field. The electroplating time is 60 seconds. The size of Ni plate used for coating is $(12.6 \times 5.3) \mathrm{cm}$. The resulting sample is first tested for coating thickness by first measuring the mass of the sample before and after coating. Layer thickness $(\delta)$ is determined by equation (9).

$\delta=\frac{W}{\rho A}$

Where $W$ the difference between the mass of the sample after coating and before the coating (gram), $\rho$ the density of the sample $\left(\mathrm{gram} / \mathrm{cm}^{3}\right)$, and $A$ the surface area of the sample $\left(\mathrm{cm}^{2}\right)$.

Second, determine the sheet resistivity $\left(R_{s}\right)$ using voltage (V) and current (I) data measured through a fourpoint probe through the equation (10).

$$
R_{s}=\frac{\pi}{\ln 2} \frac{V}{I}
$$

Third, analyze the microstructure by looking at the peak X-ray intensity data generated through the XRD test. Crystal size $\left(g_{s}\right)$ determine by the Debye-Scherrer equation that shows in equation (11).

$g_{s}=\frac{0.9 \lambda}{F W H M \cos \theta}$

where $\lambda$ the wavelength of the X-ray used, FWHM the width of the diffraction peak at the position of half the 
maximum diffraction intensity, and $\theta$ the diffraction angle.

Fourth, determine the distance between Bragg planes $(d)$ through equation (12).

$d=\frac{\lambda}{2 \sin \theta}$

\section{Results and Discussion \\ Determination of Layer Thickness}

Coatings are carried out 5 samples coded WAW-01, WAW-02, WAW-03, WAW-04, and WAW-05 that indicates the sample is coated with deposition voltage 1 , 2, 3, 4 and $5 \mathrm{~V}$, respectively. The mass measurements of the samples were carried out before coating $\left(m_{C u}\right)$ and after coating $\left(m_{\mathrm{Cu} / \mathrm{Ni}}\right)$ whose results are shown in Table 1.

Tabel 1. The mass of the sample before and after coating

\begin{tabular}{cccc}
\hline $\begin{array}{c}\text { Magnetic } \\
\text { field } \\
\text { (gauss) }\end{array}$ & $\begin{array}{c}\text { Deposition } \\
\text { Voltage } \\
\text { (V) }\end{array}$ & $\mathbf{m}_{\mathbf{C u}}(\mathbf{g})$ & $\mathbf{m}_{\mathbf{C u} / \mathrm{Ni}}(\mathbf{g})$ \\
& 1 & 1,89468 & 1,89970 \\
& 2 & 1,81606 & 1,83142 \\
200 & 3 & 1,87654 & 1,90220 \\
& 4 & 1,81730 & 1,86204 \\
& 5 & 1,89880 & 1,96412 \\
\hline
\end{tabular}

Then determine the thickness of the formed Ni layer $(\delta)$ using equation (11). The graph of the relationship between the thickness of the nickel layer formed and the deposition voltage shown in Figure 3.

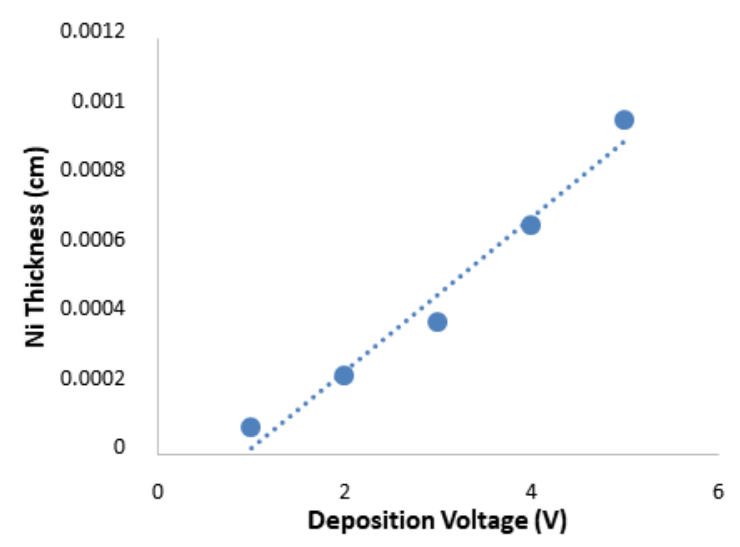

Figure 3. Graph of the Relationship between Thickness of Ni Layer Formed to Deposition Voltage

At deposition voltage 1, 2, 3, 4, and $5 \mathrm{~V}$ successively produced nickel thickness of $(7.40 \pm 0.07$; $22.66 \pm 0.07 ; 37.85 \pm 0.07 ; 65.99 \pm 0.07 ; 96.35 \pm 0.07) \times$ $10^{5} \mathrm{~cm}$. Through linear regression obtained the curve equation that represent the relationship between thickness and deposition voltage shown in equation (13).
$\delta_{B}=1.90951 \times 10^{-4}-1.423631 \times 10^{-4}$

By looking at the gradient that is positive it can be seen that the thickness of the layer formed is directly proportional to the applied deposition voltage. This is due to the increase in deposition voltage which will increase the number of electrons flowing from the anode to the cathode through the conductor. This causes an increase in the amount of ion anode material formed so that the mass of the anode material superimposed increases which also means the thickness increases. By remember that the greater the voltage indicates the higher current density, this result is suitable that obtained in previous studies that the thickness of the layer increases with increasing current density [10].

\section{Microstructure Test}

The microstructure test of the coating was done through XRD testing by firing the $\mathrm{Cu} \mathrm{K}$-alpha 1 rays which have a wavelength of $1.54060 \AA$ A on the sample. Xray diffraction intensity $(I)$ data was taken in the scattering angle range $(2 \theta)$ of $0^{\circ}$ to $100^{\circ}$. After phase identification, $\mathrm{Ni}$ and $\mathrm{Cu}$ phases are obtained at the first two peaks shown in figure 4 .

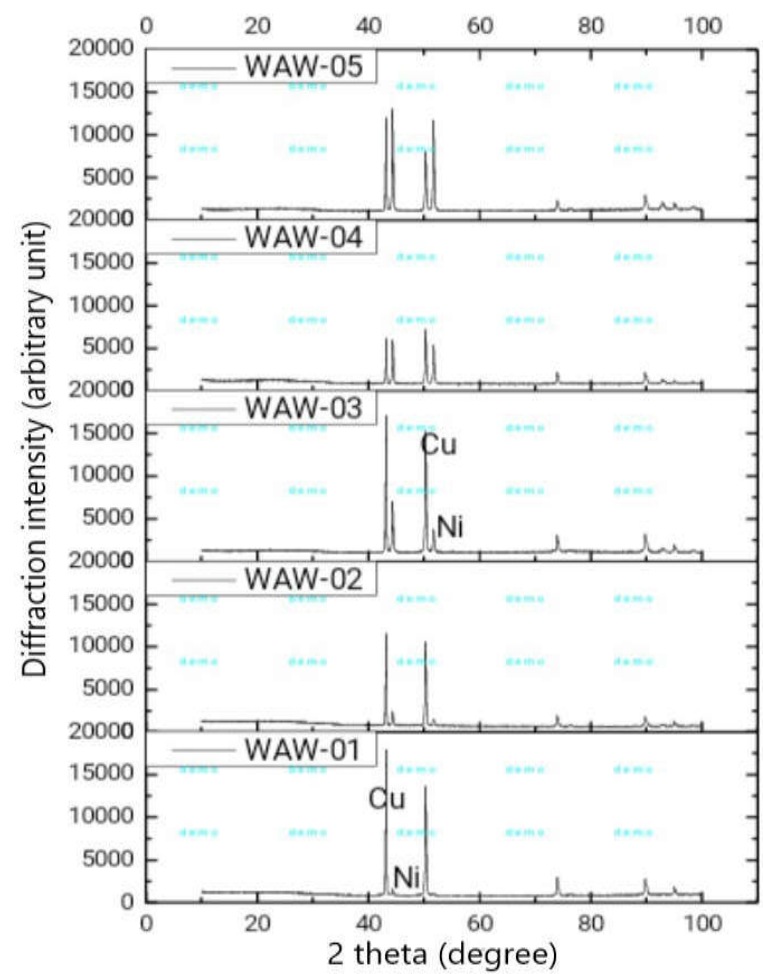

Figure 4. Results of the identification of $\mathrm{Ni}$ and $\mathrm{Cu}$ phases

Increasingly sharp of graph diffraction intensity indicates the increasing amount of diffraction counts that the detector receives. This is as a result of the increasingly orderly and lengthy arrangement of the crystal-structure atoms. The graph of diffraction intensity 
for the first peak is shown in Figure 5, where for the second peak show in Figure 6.

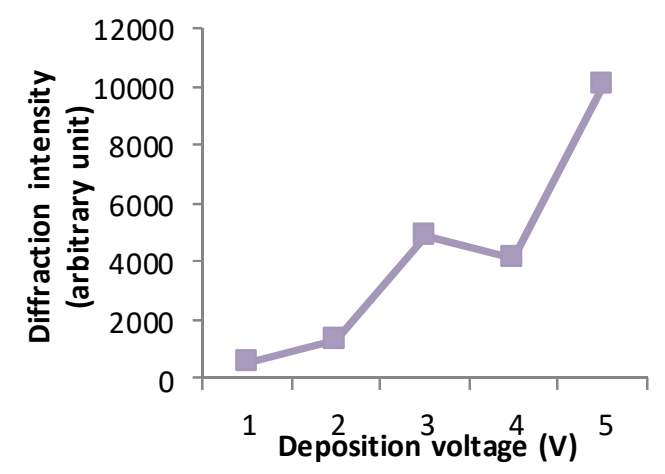

Figure 5. Graph of the relationship between diffraction intensity and deposition voltage for the first diffraction pea

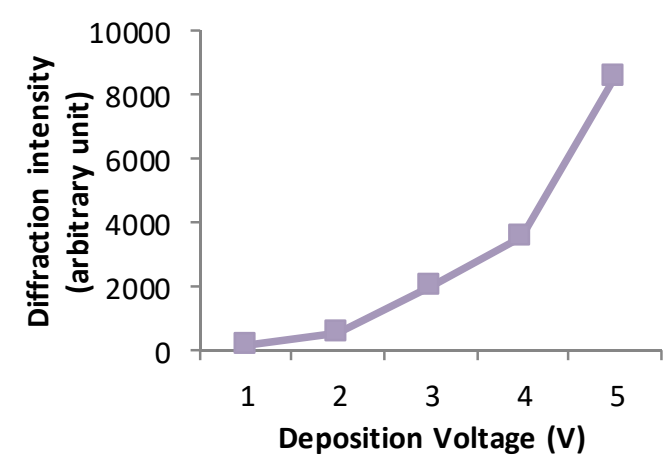

Figure 6. Graph of the relationship between diffraction intensity and deposition voltage for the second diffraction peak

By remembering the results of the layer thickness test and observing the graphs in Figures 5 and 6 it is known that the diffraction intensity tends to increase with the increase of thickness and deposition voltage. This is because by increasing the element of $\mathrm{Ni}$ on the $\mathrm{Cu}$ substrate will increase the amount of $\mathrm{Ni}$ crystals formed. By increasing the intensity of nickel diffraction the resistivity of thin film will increase because the higher intensity of diffraction indicates a more orderly arrangement of atoms [11].

In the Graph of the relationship between diffraction intensity and deposition voltage for the first diffraction peak, the intensity decrease at $4 \mathrm{~V}$ deposition voltage. This is probably due to non-uniformity of the thickness of Ni that coated, then the X-ray that is fired is not hitting on the part of the sample that represents the characteristics real sample.

Then the average crystal size is determined from the crystal size for the first and second Ni diffraction peaks. The crystal size for each diffraction peak is determined by equation (11). The relationship of the average $\mathrm{Ni}$ crystal size to the deposition voltage is shown in the Figure 7.

It can be seen in the graph in Figure 7 that crystal size increase with the increase of deposition voltage and thickness. This is consistent with the results of the previous study that increasing the number of coatings increases the size of the crystal [12]. The increase in crystal size will have an impact on decreasing sheet resistivity [13].

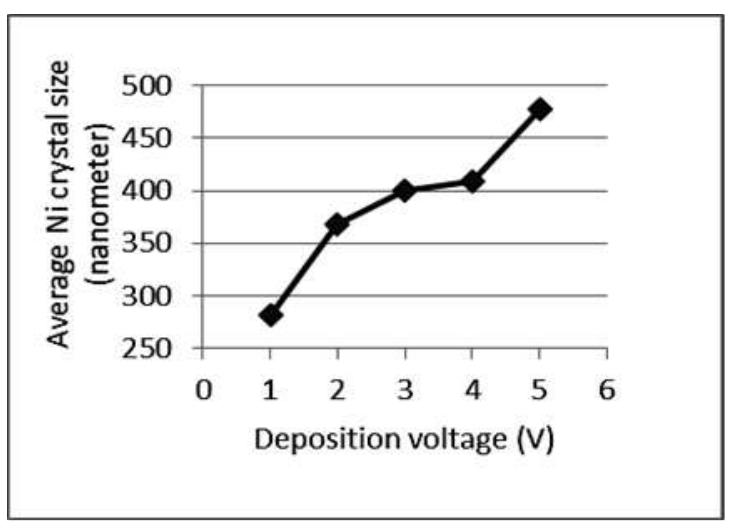

Figure 7. Graph of relationship between average Ni crystal size and deposition voltage.

Then the distance between the Bragg plane $(d)$ is determined at the peak of the first and second $\mathrm{Ni}$ diffractions, each graph shown in Figures 8 and 9.

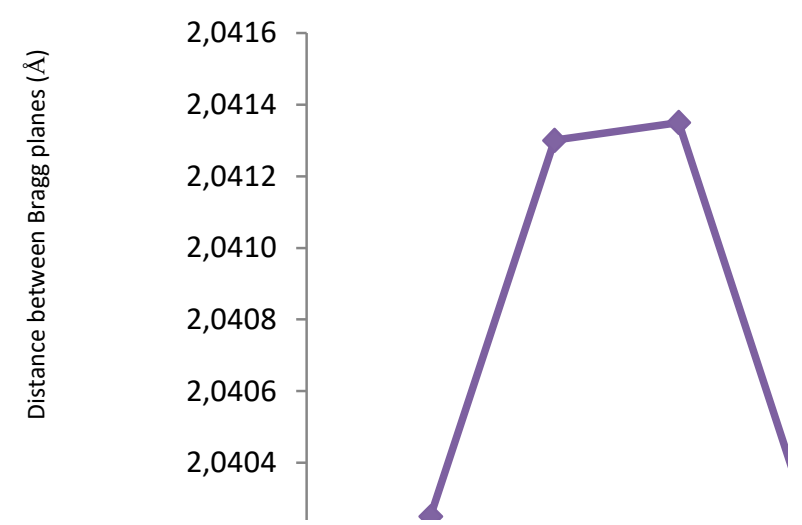

Figure 8. Graph of relationship between distance between Bragg planes for first Ni diffraction peak and deposition voltage.

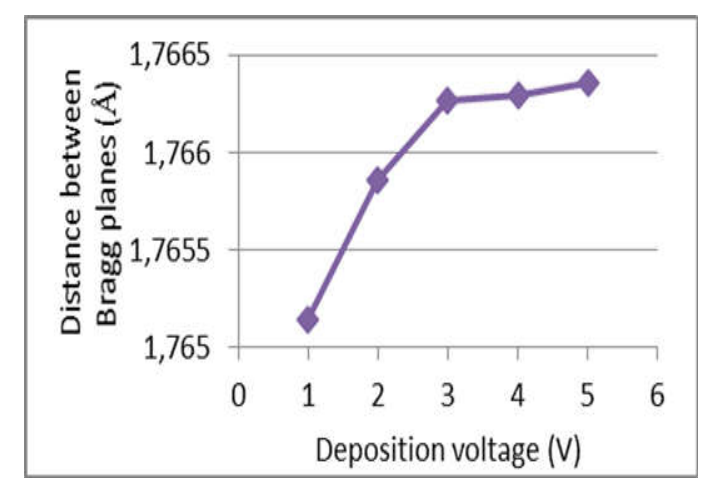

Figure 9. Graph of relationship between distance between Bragg planes for second Ni diffraction peak and deposition voltage. 
The distance between Bragg planes satisfies equation (12). Through this equation, it appears that the distance between the Bragg planes is influenced by the diffraction angle of 2 theta. Based on the diffraction peak data obtained by the XRD test, there was no phase shift in all sampel which meant the diffraction angle showed almost the same value for all sampel. This makes the distance between the Ni Bragg planes obtained is also almost equal for all samples.

The distance between these Bragg planes also affects the magnitude of sheet resistivity. The smaller the distance between Bragg planes will increase the amount of electric current flowing thereby increasing conductivity [14]. By remembering that resistivity is inversely proportional to conductivity, it means that the greater distance between Bragg planes will result in greater resistivity.

\section{Sheet Resistivity}

Samples WAW-01, WAW-02, WAW-03, WAW04, and WAW-05 were successively coated with 1, 2, 3, 4 and $5 \mathrm{~V}$ deposition voltage. Sheet resistivity test was carried out to all sample before and after coating using a four-point probe. Measurement of voltage and a current flowing in the sample is carried out five times at five different points with an input voltage made constant at 6 $\mathrm{V}$. The sheet resistivity used is the average sheet resistivity of the sheet resistivity for each measurement point. The sheet resistivity of each sample before and after the coating is shown in table 2 .

Table 2. Sheet Resistivity of sample before and after coating

\begin{tabular}{ccc}
\hline $\begin{array}{c}\text { Deposition } \\
\text { Voltage }(\mathbf{V})\end{array}$ & $\begin{array}{c}\text { Before coating: } \\
\boldsymbol{R}_{\boldsymbol{s}} \pm \boldsymbol{S}_{\boldsymbol{R} \boldsymbol{s}}(\boldsymbol{\Omega} / \mathbf{s q}) \mathbf{1 0 ^ { - 5 }}\end{array}$ & $\begin{array}{c}\text { After coating: } \\
\boldsymbol{R}_{\boldsymbol{s}} \pm \boldsymbol{S}_{\boldsymbol{R} \boldsymbol{s}}(\boldsymbol{\Omega} / \mathbf{s q}) \mathbf{1 0}^{-\boldsymbol{5}}\end{array}$ \\
\hline 1 & $4,4125 \pm 0,0001$ & $4,5003 \pm 0,0001$ \\
2 & $4,4061 \pm 0,0001$ & $4,4831 \pm 0,0001$ \\
3 & $4,4083 \pm 0,0001$ & $4,5344 \pm 0,0001$ \\
4 & $4,4120 \pm 0,0001$ & $4,5599 \pm 0,0001$ \\
5 & $4,3988 \pm 0,0001$ & $4,5266 \pm 0,0001$ \\
\hline
\end{tabular}

The graph of the relationship between sheet resistivity after coating and deposition voltage is shown in Figure 10.

It can be seen in Table 2 that after the coating is done there is an increase in the sheet resistivity of the sample. This is probably due to the impurity of $\mathrm{Cu}$ samples by $\mathrm{Ni}$ whose resistivity is higher.

There is a tendency for an increase in diffraction intensity, crystal size, and distance between Bragg planes with increasing deposition voltage. The increase in distance between Bragg planes has a more dominant in influencing the sheet resistivity value for deposition voltage 2 to $4 \mathrm{~V}$ so that the sheet resistivity value tends to increase in the deposition voltage range. While at 1 and 5 $\mathrm{V}$ deposition voltage, the diffraction intensity and crystal size factor are more dominant in influencing the resistivity value so that the sheet resistivity value decreases at the deposition voltage.

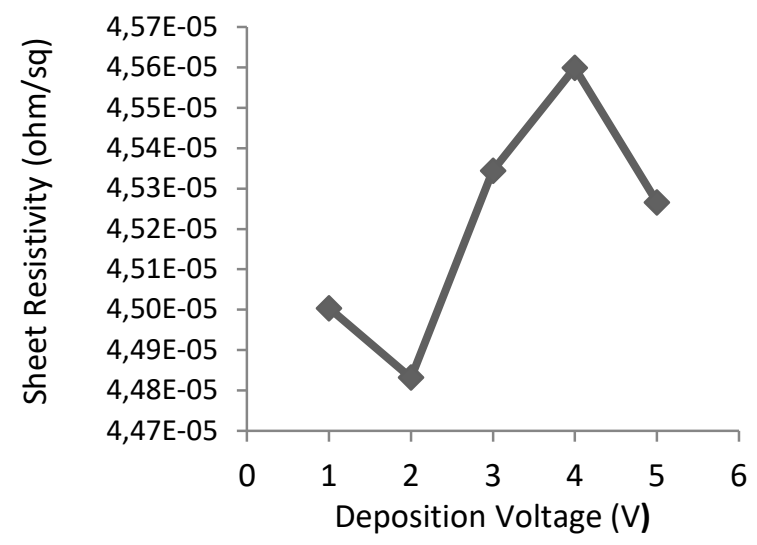

Figure 10. Graph of sheet resistivity relationship to deposition Voltage.

Another factor that causes mismatches between sheet resistivity data to crystal size, diffraction intensity, and distance between Bragg planes is the lack of precision displaying the voltage value read on the voltmeter. Nonuniformity in the thickness of the deposited Ni layer also affects, because this results in a 4 point probe not always able to measure at points that can represent the characteristics of the actual sample.

\section{Conclusion}

The effect of deposition voltage assisted by magnetic fields on the variables of the coating samples studied are as follows: (1). The thickness of the formed Ni layer increases with the increase of deposition voltage, (2). The regularity of Ni crystal-structure atoms increases with the increase of thickness and deposition voltage, the lowest regularity of the crystal-structure atoms obtained in the deposited sample with a deposition voltage of $1 \mathrm{~V}$. (3). The average Ni crystal size increases with the increase of deposition voltage. The smallest Ni crystal size in the coating sample with a deposition voltage of 1 $\mathrm{V}$, (4). Spacing between Bragg planes is almost equal for all samples, (5). The highest sheet resistivity was obtained from the sample that coated with a $4 \mathrm{~V}$ deposition voltage.

\section{Reference}

[1] N. Afsarimanesh and P. . Ahmed, "LabVIEW Based Characterization and Optimization of Thermal Sensors. International Journal on Smart Sensing and Intelligent Systems," Int. J. Smart Sens. Intell. Syst., vol. 4, no. 4, pp. 726-739, 2011.

[2] T. Chowdhury and H. Bulbul, "Design of a Temperature Sensitive Voltage Regulator for AC Load Using RTD," Int. J. Eng. Sci. Technol., vol. 2, no. 12, pp. 7896-7903, 2010.

[3] M. Toifur, Nuramalia A, Okimustava, and M. I. Sukarelawan, "Pengaruh Waktu Deposisi pada Tebal Lapisan, Struktur Mikro, Resistivitas Keping Lapisan Tipis $\mathrm{Cu} / \mathrm{Ni}$ Hasil Deposisi dengan Teknik Elektroplating," J. Mater. dan Energi Indones., vol. 7, no. 
2, pp. 33-43, 2017.

[4] R. Fiqry and M. Toifur, "Pembuatan Lapisan Tipis $\mathrm{Cu}_{1} / \mathrm{Ni}_{1} / \mathrm{Cu}_{2} / \mathrm{Ni}_{2}$ sebagai Bahan Dasar Sensor Suhu Rendah dengan Metode Electroplating pada Variasi Tegangan Deposisi. UAD: Program Studi Magister Pendidikan Fisika," UAD, 2018.

[5] P. Paridawati, "Analisa Besar Pengaruh Tegangan Listrik Terhadap Ketebalan Pelapisan Chrome Pada Pelat Baja Dengan Proses Electroplating," J. Ilm. Tek. Mesin Unisma "45" Bekasi, vol. 1, no. 1, p. 97467, 2013.

[6] M. Ebadi, W. J. Basirun, and Y. Alias, "Influence of Magnetic Field on the Electrodeposition of Ni-Co Alloy," J. Chem. Sci., vol. 122, no. 2, pp. 279-285, 2010, doi: 10.1007/s12039-010-0032-9.

[7] W. A. Wijanarka and M. Toifur, "Sintesis Lapisan Tipis $\mathrm{Cu} / \mathrm{Ni}$ dengan Metode Elektroplating Berbantuan Medan Magnet pada Variasi Rapat Arus," UAD, 2018.

[8] W. Giurlani et al., "Electroplating for Decorative Applications: Recent Trends in Research and Development," Coatings, vol. 8, no. 8. 2018, doi: 10.3390/coatings 8080260 .

[9] S. Glasstone, "Introduction to Electrochemistry," 1962, doi: 10.1007/978-1-349-22721-1.
[10] N. Zaimah, A. Nurain, and S. Hussain, "Effects of Current Density on Size and Surface Morphology of High Speed Direct Nano-Crystalline Nickel Plating on Titanium Surface," ARPN J. Eng. Appl. Sci., vol. 10, no. 17, pp. 7864-7869, 2015.

[11] S. B. Eadi, H. S. Song, H. D. Song, J. Oh, and H. D. Lee, "Nickel Film Deposition with Varying RF Power for the Reduction of Contact Resistance in NiSi," Coatings, vol. 9, no. 6, 2019, doi: 10.3390/coatings9060365.

[12] M. Moradi-Haji Jafan, M.-R. Zamani-Meymian, R. Rahimi, and M. Rabbani, "The Effect of Solvents and the Thickness on Structural, Optical and Electrical Properties of ITO Thin Films Prepared by a Sol-Gel Spin-Coating Process," J. Nanostructure Chem., vol. 4, no. 1, 2014, doi: 10.1007/s40097-014-0089-y.

[13] Y. Zhou, I. Matsubara, W. Shin, N. Izu, and N. Murayama, "Effect of Grain Size on Electric Resistivity and Thermopower of (Ca 2.6Bi0.4)Co4O9 Thin Films," $J$. Appl. Phys., vol. 95, no. 2, pp. 625-628, 2004, doi: 10.1063/1.1631732.

[14] S. Sugianto et al., "Pengaruh Temperatur Annealing Pada Sifat Listrik Film Tipis Zinc Oksida Doping Aluminium Oksida," J. MIPA, vol. 39, no. 2, pp. 115-122, 2016. 